\section{Factorial study of diesel engine oil contamination effects on steel and ceramic sliding contacts}

\author{
P Ramkumar' (D, TJ Harvey ${ }^{2}$, RJK Wood ${ }^{2}$, AD Rose , $^{3}$, \\ DC Woods ${ }^{3}$ and SM Lewis ${ }^{3}$
}

Proc IMechE Part J:

J Engineering Tribology

$0(0) \mathrm{I}-15$

(C) IMechE 2018

Article reuse guidelines:

sagepub.com/journals-permissions

DOI: $10.1177 / 1350650118794730$

journals.sagepub.com/home/pij

(SAGE

\begin{abstract}
The present work investigates the effects of diesel contaminants and their interaction on tribological properties for bearing steel $(\mathrm{En} 3 \mathrm{I})$ and ceramic $\left(\mathrm{Si}_{3} \mathrm{~N}_{4}\right)$ sliding contacts using a factorial study. The contaminants are soot, sulphuric acid, moisture and oxidation, and each contaminant has three different level of concentration (low, medium and high) in the test matrix. The factorial test matrix consisted of 20 tests, constructed from a quarter fractional factorial test matrix with four points at the medium values for the contaminants. Results from this matrix required six further tests to elucidate aliased pairs of interactions using Bayesian model selection. A pin-on-disc tribometer was used to carry out all the experiments. All tests were carried out under ambient conditions at $5 \mathrm{~m} / \mathrm{s}$ sliding speed and contact stress of I.52.05 GPa to simulate a valve-train in a diesel engine with fully formulated heavy-duty diesel engine oil used as lubricant. Four different tribological properties were studied. The factorial study showed that charge was influenced by tribocouple material; the silicon nitride discs produced higher charge than steel discs. However, it was opposite for friction; the silicon nitride disc gave lower friction and the pins showed higher friction than their steel counterparts. For wear scar and temperature, soot contaminant was found to be important. The two important interactions were found for the charge response, with the interaction between sulphuric acid and pin material being more important than sulphuric acidoxidation interaction. Similarly to charge, an interaction between sulphuric acid and pin material interaction was found for friction.
\end{abstract}

\title{
Keywords
}

Bayesian model selection, ceramic, contamination, factorial design, sliding wear, soot

Date received: 16 December 2017; accepted: 24 July 2018

\section{Introduction}

In modern automotive engines, especially in diesel engines, consumer demand for ever increasing service intervals has led to longer oil drain periods. Consequently, without improvements to lubricants, this will lead to an increase in contamination levels and in turn, reduced engine efficiency and increased possibility of system failure (due to increases in viscosity and the potential of oil starvation leading to scuffing).

There is a wide range of contaminants that are encountered by diesel engines (see Table 1). From this list, the top four (soot, water, oxidation and sulphuric acid) were chosen for study.

Soot is a major contaminant in diesel engines. Elemental analysis of particulate matter shows that oil particulates consist mostly of carbon (88.3\%) with other species ${ }^{1}$ as shown in Figure 1. Concentration levels as high as $9.3 \%$ soot by weight have been reported in oils. ${ }^{2}$
Oil can become contaminated by water through leakage from weak seals and from moisture entering into the lubricant stream from ambient sources including combustion and condensation. Typically, the amount of water contamination varies across the range $0.2-10 \%$ by weight. ${ }^{3,4}$

Lubricating oils may contain many corrosive species such as naturally occurring sulphur compounds, acidic combustion products (oxyacids of nitrogen and

\footnotetext{
'Department of Mechanical Engineering, IIT Madras, India

${ }^{2}$ Faculty of Engineering and the Environment, National Centre for Advanced Tribology at Southampton (nCATS), University of Southampton, Highfield, UK

${ }^{3}$ Faculty of Mathematical Sciences, Southampton Statistical Sciences Research Institute, University of Southampton, Highfield, UK
}

\section{Corresponding author:}

P Ramkumar, Indian Institute of Technology Madras, 408, Machine Design Section, Adyar, Chennai, Tamil Nadu 600036, India. Email: ramkumar@iitm.ac.in 
Table I. Lubricant contaminants types and their origins. ${ }^{5}$

\begin{tabular}{|c|c|c|}
\hline Type & Primary sources & Major problems \\
\hline Soot & Combustion blow-by & $\begin{array}{l}\text { Interfere with additives, abrasive wear, } \\
\text { heavy deposits, oil thickening/gelation }\end{array}$ \\
\hline Water & $\begin{array}{l}\text { Combustion blow-by, } \\
\text { coolant leakage }\end{array}$ & Metal corrosion, promotes lubricant breakdown \\
\hline Oxidation of oil & $\begin{array}{l}\text { Thermal degradation/ } \\
\text { contact with atmospheric air }\end{array}$ & Oil thickening \\
\hline Acids & $\begin{array}{l}\text { Combustion blow-by, } \\
\text { lubricant breakdown }\end{array}$ & Metal corrosion, catalysis of lubricant breakdown \\
\hline Metallic particles & Component wear & $\begin{array}{l}\text { Abrasion, surface roughening leading to adhesion, } \\
\text { catalysis of lubricant breakdown }\end{array}$ \\
\hline Metal oxides & $\begin{array}{l}\text { Component wear, } \\
\text { oxidation of metallic particles }\end{array}$ & Abrasion, surface roughening leading to adhesion \\
\hline $\begin{array}{l}\text { Minerals (i.e. silica sand) } \\
\text { and dirt }\end{array}$ & Induction air & Abrasion, surface roughening leading to adhesion \\
\hline Exhaust gases & Combustion blow-by & Acids promoting lubricant breakdown \\
\hline Glycol & Coolant leakage & Lubricant breakdown \\
\hline Fuel & Blow-by-rich mixture & Lubricant breakdown and dilution of engine oil \\
\hline
\end{tabular}

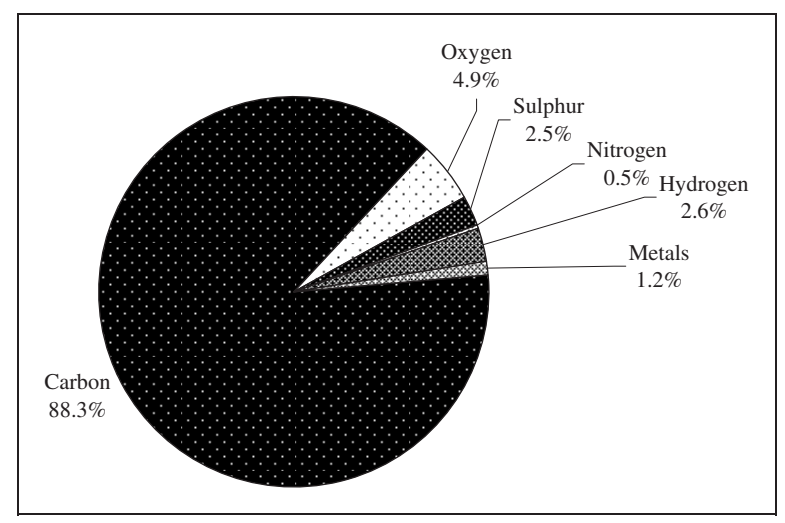

Figure I. Elemental composition of the typical diesel particulate matter by mass.

sulphur), acidic oil oxidation products and anti-wear and extreme pressure additives. All of these chemically react with metals and this reaction is enhanced within the tribocontact. Abrasion can promote corrosive wear by removing surface tribofilms. Corrosion in diesels is typically controlled by overbased detergents that neutralise the (sulphuric) acids produced by combustion. Increased wear in diesel engines using exhaust gas recirculation method can be associated with corrosion due to the formation of sulphuric acid by reaction of sulphur oxides (formed during combustion) with condensed water. When the acid reaches the oil sump it reduces the total base number $(\mathrm{TBN})$ of the lubricating oil and thereby affects the properties of the lubricating oil. ${ }^{6}$ Sulphuric acid is also known to breakdown tribofilms on cam material surfaces and causes extreme corrosive wear. ${ }^{7}$ Akiyama et al. ${ }^{7}$ showed how the TBNs of oils decrease with increasing sulphur content in the oils in the range $0.1-0.4 \% \mathrm{w} / \mathrm{w}$. They also reported experiments to evaluate the rate at which oils neutralise the addition of $0.1 \mathrm{ml}$ sulphuric acid. The type of metal detergent present was found to greatly influence neutralisation rates.

Oxidation is a natural phenomenon and is considered to be the leading indicator of oil degradation. ${ }^{8}$ In this work, the model diesel lubricant was oxidised for periods of 2, 4 and $10 \mathrm{~h}$ in a bulk lube oil oxidation bench test as described by Yamaguchi et al. ${ }^{9}$ In this test the rate of oxygen uptake by a given volume of oil, with added metal catalyst, is monitored at constant pressure and temperature $\left(171^{\circ} \mathrm{C}\right.$ and 2 psig $\mathrm{O}_{2}$ ).

An experimental study using a two-level fractional factorial design ${ }^{10}$ was planned to investigate these four contaminants (soot, oxidation, water and acid), together with two tribocontact materials (steel and silicon). A 20-run test matrix was employed, consisting of a six-factor one-fourth replicate fractional factorial design with four additional model checking runs using mid-levels of the contaminants. Subsequently, six further tests were performed to enable pairs of interactions that were aliased in the initial experiment to be distinguished.

\section{Experimental}

Tests were performed using an instrumented pinon-disc (PoD) tribometer, as shown in Figure 2. A button-type inductive electrostatic sensor was used in all experiments (details are given in Harvey et al., ${ }^{11,12}$ Wang et al. ${ }^{13}$ and Morris et al. ${ }^{14}$ ). The sensor had a sensing area of $7.85 \times 10^{-5} \mathrm{~m}^{2}$ (10 $\mathrm{mm}$ diameter sensing face) and was positioned approximately $0.5 \mathrm{~mm}$ above the disc surface. The 
button-type electrostatic sensor was connected to a signal-conditioning unit, with switchable high- and low-pass filters, set at $1 \mathrm{~Hz}$ and $10 \mathrm{kHz}$, respectively. The incorporation of a high pass was designed such that it monitored only dynamic charge events and was insensitive to static/constant charges.

Electrostatic sensing technique is well established for monitoring wear in lubricated contacts. The measured charge is directly indicating the deterioration of the contact surfaces and it is sensitive to steel, ceramic contacts and quality of lubricants. ${ }^{15,16}$ Further, impedance-based sensors are effective to detect changes in oil quality and make them active lubrication monitoring. ${ }^{17}$

A force transducer was used for measuring friction and an infrared pyrometer was used to monitor the temperature of the wear track on the disc as close as possible to the tribocontact. A linear variable differential transformer (LVDT) was used to monitor the linear wear of the pin and disc.

A standard Zeitfuchs cross-arm type (ASTM D 445 and ISO 3104) size 6 viscometer, supplied by Cannon Instrument Company (USA), was employed to measure kinematic viscosity of the contaminated test lubricants. The conductivity measurements were performed with a Wolfson Electrostatic liquid L30 conductivity meter. ${ }^{18}$

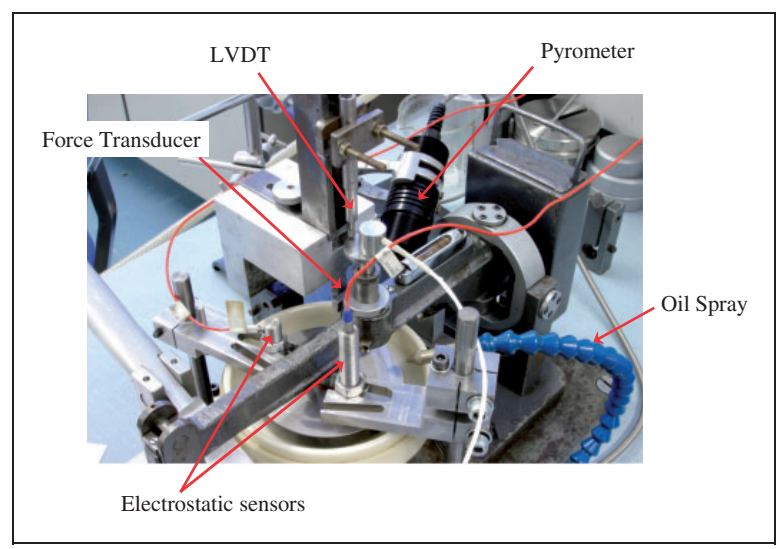

Figure 2. Instrumentation employed in monitoring PoD tribometer. LVDT: linear variable differential transformer.

\section{Test conditions}

The tests used $6 \mathrm{~mm}$ diameter balls and $100 \mathrm{~mm}$ diameter discs; material properties are provided in 'Material selection' section. All tests were carried out under ambient conditions (temperature $=18$ $28^{\circ} \mathrm{C}$, relative humidity $=40-70 \%$ ) at a sliding speed of $5 \mathrm{~m} / \mathrm{s}$ and a load of $30 \mathrm{~N}(2.05-2.55 \mathrm{GPa}$ initial Hertzian contact pressure, depending on material combination). These conditions are mildly accelerated compared with typical valve-train entrainment velocities and contact pressures. Contact stresses in the range 1.7-2.07 $\mathrm{GPa}$ have been reported for lowemission diesel engines. ${ }^{19}$ Entrainment velocities have been reported as high as $7 \mathrm{~m} / \mathrm{s}$ for a 2.01 four-cylinder GM Ricardo Hydra Gasoline engine ${ }^{20}$ and $4.8 \mathrm{~m} / \mathrm{s}$ for a Sequence VE engine tappet system. ${ }^{21}$

\section{Material selection}

The bearing steel used in testing is EN31 (B.S. 534A99, AISI E 52100 steel), which has an elemental composition of $0.95-1.10 \% \mathrm{C}, 0.10-0.35 \% \mathrm{Si}, 0.40$ $0.70 \% \mathrm{Mn}, 1.20-1.60 \% \mathrm{Cr}$, remainder Fe. The silicon nitride bearing balls were obtained from Spheric Trafalgar Ltd and the discs were obtained from H.C. Starck Ceramics, Germany. The material properties are shown in Table 2.

\section{Test procedure}

Prior to loading the disc was rotated (at the desired speed) for $3 \mathrm{~min}$ and then the lubricant (see 'Uncontaminated lubricating oil' section) was applied for $5 \mathrm{~min}$, and background measurements were performed during this period. An initial load of $1.76 \mathrm{~N}$ was increased at a rate of $0.0714 \mathrm{~N} / \mathrm{s}$ to a final load of $30 \mathrm{~N}$ over a period of $7 \mathrm{~min}$; tests were run for a further $1 \mathrm{~h}$ duration as a steady-state period.

\section{Uncontaminated lubricating oil}

The uncontaminated lubricating oil is a typical commercially available heavy-duty diesel engine oil, consisting of succinimide dispersants, sulphonate and phenate detergents, secondary zinc dithiophosphate

Table 2. Properties and dimensions of bearing steel balls (pins) and discs used in experiments.

\begin{tabular}{|c|c|c|c|c|}
\hline \multirow{2}{*}{$\frac{\text { Material }}{\text { Component }}$} & \multicolumn{2}{|c|}{ Bearing steel (EN3I) } & \multicolumn{2}{|l|}{ Silicon nitride } \\
\hline & Ball (pin) & Disc & Ball (pin) & Disc \\
\hline Density $\left(\mathrm{g} / \mathrm{cm}^{3}\right)$ & 7.8 & & $3.22-3.25$ & 3.22 \\
\hline Poisson's ratio & 0.30 & & 0.28 & 0.28 \\
\hline Young's modulus (GPa) & 210 & & 300 & 290 \\
\hline $\mathrm{R}_{\mathrm{a}}(\mu \mathrm{m})^{\mathrm{a}}$ & $0.050 \pm 0.006$ & $0.050 \pm 0.002$ & $0.050 \pm 0.008$ & $0.050 \pm 0.002$ \\
\hline Hardness $\left(\mathrm{Hv}_{50}\right)^{\mathrm{a}}$ & $980 \pm 44$ & $218 \pm 5$ & $1800 \pm 45$ & $1550 \pm 26$ \\
\hline
\end{tabular}

a Measured value. 
amine antioxidant, phenol antioxidant, foam inhibitor, viscosity index improver and group 1 base oils.

Contamination mixing procedure. The mixing of the contaminants into the uncontaminated oil is described below. The order in which the contaminants were added to both the oxidised and uncontaminated oil (both supplied by Chevron Oronite) is the same as the order in which they are presented below.

Oxidation: The oil was heated to temperature $171{ }^{\circ} \mathrm{C}$ and constant $\mathrm{O}_{2}$ pressure was maintained in the presence of a metal catalyst for the appropriate time.

Diesel soot mixing: The diesel soot was added to the oil while mechanical stirring took place and homogenised in an ultrasonic bath for an hour. The soot was obtained from the overhead soot recovery system of the Chevron Oronite engine testing facility in Omaezaki, Japan. Average particle size was 10 $40 \mathrm{~nm}$ and chemical composition was $80 \%$ carbon, $17 \%$ oxygen, $1 \%$ nitrogen, $1 \%$ zinc and $1 \%$ sulphur.

Water mixing: The water was added to the oil during mechanically stirring and homogenised in an ultrasonic bath for an hour.

Sulphuric acid mixing: The test oil was heated to $80^{\circ} \mathrm{C}$ and the required amount of acid added drop by drop, while the oil was continuously stirred using a magnetic stirrer.

\section{Processing of online data}

Online measurements. Online measurements were taken with a PC data acquisition system, using a Data Translation DT321 16-bit eight-channel A/D card. Data from the strain gauge, pyrometer, LVDT and electrostatic sensor were acquired at a rate of $4 \mathrm{kHz}$. These details were processed to produce an average (root mean square for the electrostatic sensor) at a rate of one point per second.

Specific wear rates (SWRs). The SWR was calculated using post-test measurements (for details, see 'Posttest analysis' section).

The volume loss of the disc, $V L_{\text {disc }}$, was calculated using equation (1)

$$
V L_{\text {disc }}=\pi D A
$$

where $D$ is the wear track diameter of the disc and $A$ is the average track cross-sectional area.

The height of the worn ball $(h)$ can be calculated by equation (2)

$$
h=R-\left(\left(R^{2}-0.25\right) d^{2}\right)^{0.5}
$$

where $R$ is the radius of the ball and $d$ is the wear scar diameter of the ball. From this the volume loss of the worn pin, $V L_{p i n}$, can be obtained from equation (3)

$$
V L_{p i n}=\frac{\pi}{3} h^{2}(3 r-h)
$$

The $S W R$ of the ball and disc can be calculated from equation (4)

$$
S W R=\frac{V L}{F \times S D}
$$

where $F$ is the force (load) and $S D$ is the sliding distance. The units used for SWR in this paper are $\mathrm{mm}^{3} / \mathrm{N} \mathrm{m}$.

\section{Steady-state measurements}

Figure 3 shows a typical output from the online measurements. From such outputs, several parameters are recorded:

- the average for the steady-state period of coefficient of friction $(\mu)$;

- the average for the steady-state period of temperature;

- the difference between the averages for the steadystate period temperature and room temperature;

- the average for the steady-state period of charge;

\section{Post-test analysis}

Two optical microscopes, an Olympus BH and Olympus BH-2, were employed to measure and image pin wear scars. In addition, a XYRIS 4000WL TaiCaan Technologies 3D profilometer was employed to examine wear scars. A JSM 6500F thermal field emission scanning electron microscope equipped with energy dispersive X-ray microanalysis spectrometer (Oxford Inca 300 EDS) was employed to analyse wear mechanisms. However, for the statistical analysis the wear mechanisms from the experiment were not focused in this paper

\section{Design of test matrix}

Factors and levels. A total of six factors were chosen in the experimental design and these included the four contaminants (soot, oxidation, sulphuric acid and moisture), as well as the disc and pin materials; these have been designated from $\mathrm{A}$ to $\mathrm{F}$, as outlined in Table 3 .

In addition, two uncontrollable covariates (viscosity and conductivity) associated with the contaminated oil properties were measured. Neither of these was found to be useful in the statistical modelling.

Experimental constraints. Due to availability of materials, only tests with steel discs could be performed at first. 


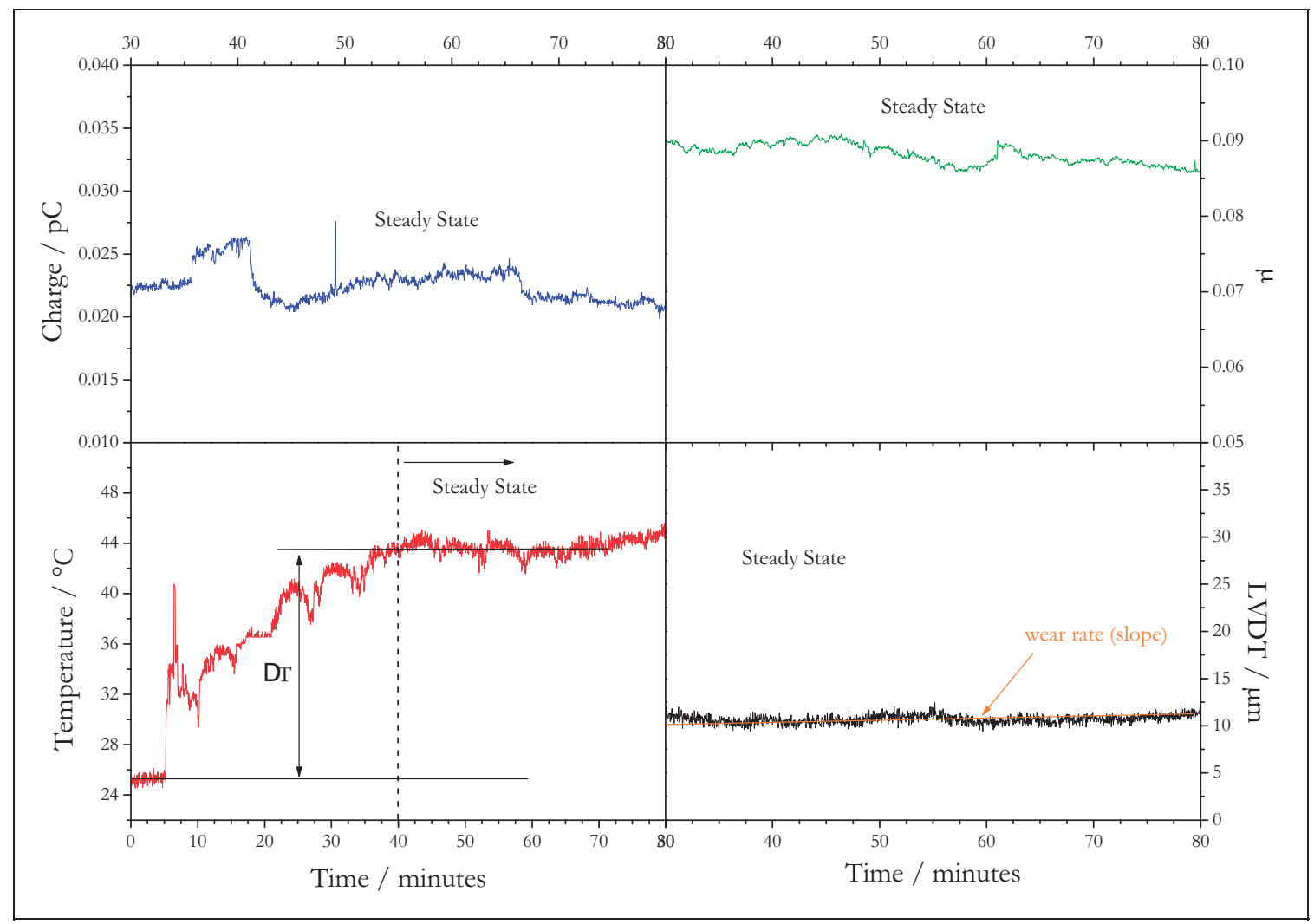

Figure 3. Measurement of online steady-state parameters (Run 4 is shown for illustration). LVDT: linear variable differential transformer.

Table 3. Factors and levels.

\begin{tabular}{lllll}
\hline & Factor & $-\mathrm{I}$ & Midpoint & $\mathrm{I}$ \\
\hline A & Disc material & Steel & & Silicon nitride \\
B & Pin material & Steel & & Silicon nitride \\
C & Soot & 0 & $5 \mathrm{wt} \%$ & $10 \% \mathrm{wt}$ \\
D & Oxidation & 0 & $5 \mathrm{~h}$ & $10 \mathrm{~h}$ \\
E & Sulphuric acid & 0 & $1.25 \mathrm{mM}$ & $2.5 \mathrm{mM}$ \\
F & Moisture & 0 & $1.25 \%$ & $2.50 \%$ \\
\hline
\end{tabular}

Therefore, the tests were performed in two batches, the first with steel discs and the second with silicon nitride discs. The number of tests was limited to 20 .

Prior information on interactions. After discussions with industrial collaborators, likely interactions between the factors were identified as follows:

- Sulphuric acid and moisture content

- Soot and oxidation

- Soot and sulphuric acid

- Oxidation and sulphuric acid

Design of the first experiment. The constraint of restricted randomisation was incorporated through the use of a factorial split-plot design, ${ }^{22}$ with one 'whole-plot' factor (disc material, labelled A) and five 'sub-plot' factors (B-F).
As only 20 tests were available, and the full factorial design with each factor taking two values would require $2^{6}=64$ tests, a one-fourth replicate fractional factorial design was used with 16 runs. The fraction was chosen so that the four interactions thought most likely to be important could be estimated independently of the main effects of each individual factor and independently of each other. However, these interactions cannot be estimated independently of the other interactions. These dependencies must be taken into account in the analysis.

In addition, four tests were conducted at the midpoints of the quantitative variables, one at each combination of the disc and pin settings. The factors and their levels are shown in Table 3 and the test matrix is detailed in Table 4.

\section{Results and discussion}

The structure of the results section will be details of results from primary testing, identification of secondary test matrix and final results (combination of all factorial tests).

\section{Primary testing}

The results for each experimental run given in Table 5 are used in the statistical analysis.

Table 5 shows the overall response of charge, coefficient of friction, wear scar diameter, SWR and 
Table 4. Factorial test matrix.

\begin{tabular}{|c|c|c|c|c|c|c|}
\hline Run & Disc material $(\mathrm{A})$ & Pin material (B) & $\begin{array}{l}\text { Soot (C) } \\
(\%)\end{array}$ & $\begin{array}{l}\text { Oxidation (h) } \\
\text { at } 170^{\circ} \mathrm{C}(\mathrm{D})\end{array}$ & $\begin{array}{l}\text { Sulphuric acid } \\
\text { (E) }(\mathrm{mM})\end{array}$ & $\begin{array}{l}\text { Moisture } \\
\text { content (F) (\%) }\end{array}$ \\
\hline I & Steel & Silicon nitride & 0 & 10 & 0 & 0 \\
\hline 2 & Steel & Silicon nitride & 10 & 10 & 0 & 2.5 \\
\hline 3 & Steel & Steel & 5 & 5 & 1.25 & 1.25 \\
\hline 4 & Steel & Steel & 0 & 10 & 2.5 & 2.5 \\
\hline 5 & Steel & Steel & 10 & 0 & 0 & 2.5 \\
\hline 6 & Steel & Steel & 0 & 0 & 0 & 0 \\
\hline 7 & Steel & Silicon nitride & 0 & 0 & 2.5 & 2.5 \\
\hline 8 & Steel & Silicon nitride & 5 & 5 & 1.25 & 1.25 \\
\hline 9 & Steel & Steel & 10 & 10 & 2.5 & 0 \\
\hline 10 & Steel & Silicon nitride & 10 & 0 & 2.5 & 0 \\
\hline II & Silicon nitride & Silicon nitride & 0 & 10 & 2.5 & 0 \\
\hline 12 & Silicon nitride & Steel & 0 & 0 & 2.5 & 0 \\
\hline 13 & Silicon nitride & Steel & 5 & 5 & 1.25 & 1.25 \\
\hline 14 & Silicon nitride & Steel & 10 & 0 & 2.5 & 2.5 \\
\hline 15 & Silicon nitride & Silicon nitride & 10 & 0 & 0 & 0 \\
\hline 16 & Silicon nitride & Silicon nitride & 10 & 10 & 2.5 & 2.5 \\
\hline 17 & Silicon nitride & Silicon nitride & 0 & 0 & 0 & 2.5 \\
\hline 18 & Silicon nitride & Silicon nitride & 5 & 5 & 1.25 & 1.25 \\
\hline 19 & Silicon nitride & Steel & 10 & 10 & 0 & 0 \\
\hline 20 & Silicon nitride & Steel & 0 & 10 & 0 & 2.5 \\
\hline
\end{tabular}

Table 5. Experimental measurements, employed in the factorial analysis, for each run number.

\begin{tabular}{|c|c|c|c|c|c|c|}
\hline \multirow[b]{2}{*}{ Run } & \multirow[b]{2}{*}{ Charge (pC) } & \multirow[b]{2}{*}{ COF } & \multicolumn{2}{|c|}{ Temperature $\left({ }^{\circ} \mathrm{C}\right)$} & \multirow{2}{*}{$\begin{array}{l}\text { Wear scar } \\
\text { radius }(\mathrm{mm})\end{array}$} & \multirow{2}{*}{$\begin{array}{l}\text { Specific wear } \\
\text { rate }\left(\mathrm{mm}^{3} / \mathrm{N} \mathrm{m}\right)\end{array}$} \\
\hline & & & Steady state & $\Delta \mathrm{T}$ & & \\
\hline I & 0.025 & 0.107 & 40.3 & 22.3 & 0.106 & $4.3 \mathrm{E}-\mathrm{II}$ \\
\hline 2 & 0.022 & 0.093 & 55.0 & 34.0 & 0.255 & $5.0 \mathrm{E}-\mathrm{II}$ \\
\hline 3 & 0.022 & 0.169 & 66.3 & 41.3 & 0.480 & 7.IE-II \\
\hline 4 & 0.021 & 0.084 & 38.3 & 18.3 & 0.142 & $1.4 \mathrm{E}-10$ \\
\hline 5 & 0.023 & 0.076 & 64.5 & 42.0 & 0.418 & $1.4 \mathrm{E}-10$ \\
\hline 6 & 0.023 & 0.114 & 36.7 & 18.1 & 0.141 & $3.6 \mathrm{E}-10$ \\
\hline 7 & 0.022 & 0.086 & 41.1 & 20.1 & 0.106 & $6.4 \mathrm{E}-10$ \\
\hline 8 & 0.037 & 0.106 & 59.5 & 39.4 & 0.238 & 8.IE-10 \\
\hline 9 & 0.021 & 0.096 & 50.1 & 30.6 & 0.448 & $8.8 \mathrm{E}-10$ \\
\hline 10 & 0.025 & 0.084 & 58.9 & 36.8 & 0.250 & I.IE-09 \\
\hline 11 & 5.393 & 0.069 & 54.0 & 28.0 & 0.120 & I.3E-09 \\
\hline 12 & 14.406 & 0.073 & 55.9 & 32.9 & 0.263 & I.5E-09 \\
\hline 13 & 26.748 & 0.078 & 56.0 & 32.0 & 0.255 & I.5E-09 \\
\hline 14 & 10.681 & 0.068 & 63.9 & 33.9 & 0.318 & I.6E-09 \\
\hline 15 & 13.157 & 0.095 & 60.9 & 29.9 & 0.311 & $3.2 \mathrm{E}-09$ \\
\hline 16 & 3.574 & 0.088 & 65.6 & 40.6 & 0.225 & 3.5E-09 \\
\hline 17 & 6.755 & 0.096 & 56.2 & 32.2 & 0.180 & 8.8E-09 \\
\hline 18 & 28.596 & 0.100 & 58.9 & 32.9 & 0.220 & I.IE-08 \\
\hline 19 & 6.053 & 0.052 & 57.0 & 32.0 & 0.400 & I.4E-08 \\
\hline 20 & 6.819 & 0.064 & 51.4 & 28.4 & 0.208 & I.8E-08 \\
\hline
\end{tabular}

COF: coefficient of friction. 
temperature rise for all the experiments. Without considering any contaminant effect, the SWR varies from $4.3 \times 10^{-11}$ to a maximum of $1.8 \times 10^{-8}$, that is approximately 400 times higher value, while the other parameters did not show such huge variation in the experiments.

The statistical results are presented as a series of half-normal plots that allowed the assessment of the 14 factorial effects that can be estimated from the data (main effects and aliased pairs of two-factor interactions, excluding the main effect of disc material). The plot compares the estimated effects to the distribution of the absolute value of a normal random variable with mean 0 . Identification of important factorial effects then becomes a graphical outlier detection problem. If no factors have a substantive effect on the response of interest, the factorial effects will form a sample from a normal distribution with mean zero, and hence the points in the half-normal plot will form a straight line. Any points that fall away from the line are candidates to have an important effect on that response and should be followed up in subsequent experimentation. Judgement of which points are not consistent with a straight line is usually performed 'by eye'; half-normal plots provide an informal 'significance test' for small factorial experiments that do not permit the estimation of background variability required for conventional hypothesis testing. ${ }^{23}$ In each plot, we label those factorial effects whose estimates we judge to be sufficiently far from the straight line to indicate potential importance; in most cases, this decision is clear and straightforward.

To generate these plots, a linear statistical model was fitted to each response, with terms consisting of an overall mean, six factor main effects (for factors $\mathrm{A}-\mathrm{F}$, see Table 3) and the two-factor interactions between pairs of factors $\mathrm{A}: \mathrm{D}, \mathrm{A}: \mathrm{E}, \mathrm{B}: \mathrm{C}, \mathrm{C}: \mathrm{D}, \mathrm{C}: \mathrm{E}$, $\mathrm{D}: \mathrm{E}$ and $\mathrm{E}: \mathrm{F}$. It should be remembered that each of these interaction effects is aliased with another twofactor interaction, and hence cannot be estimated, or interpreted, independently. Hence follow-up experiments will be necessary.

The validity of the model assumptions was checked by examination of residual diagnostics, that is graphical examination of the differences between the data and the model predictions for each response. For charge and wear scar, it was found that a log transform was appropriate. For temperature, the residual analysis was not satisfactory, and hence no results are reported for this response in the primary testing stage.

Note that it was not appropriate to include the main effect of factor A (disc material) in the halfnormal plots due to the restricted randomisation applied to the test matrix. The effect of this factor was potentially measured on a different scale to the effects of the subplot factors, and detection of other influences (interactions and main effects) may be obscured by its inclusion.
On each plot, the factorial effects that lie away from the straight line formed by the other unimportant effects are labelled. For interactions, this label includes only one interaction from each aliased pair.

Charge. From the half-normal plot for charge, shown in Figure 4, one aliased pair of interactions and one main effect are identified. The main effects are of factor D (oxidation) and the aliased pair of interactions $\mathrm{AD}$ (disc material and oxidation) and $\mathrm{BE}$ (between pin material and sulphuric acid).

Coefficient of friction. From the half-normal plot for coefficient of friction, shown in Figure 5, two aliased pairs of interactions and one main effect are identified. The two interactions are AD (disc material - oxidation), along with its' aliased pair BE (pin material sulphuric acid), and DE (oxidation - sulphuric acid), along with its' aliased pair AB (disc material - pin material)

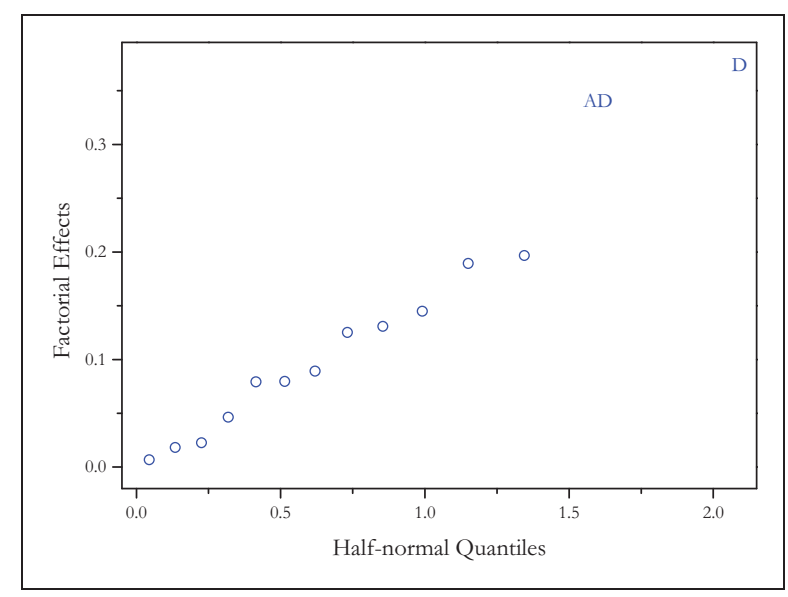

Figure 4. Half-normal plot (without A) for logarithmic charge (see Table 3 for factor labels).

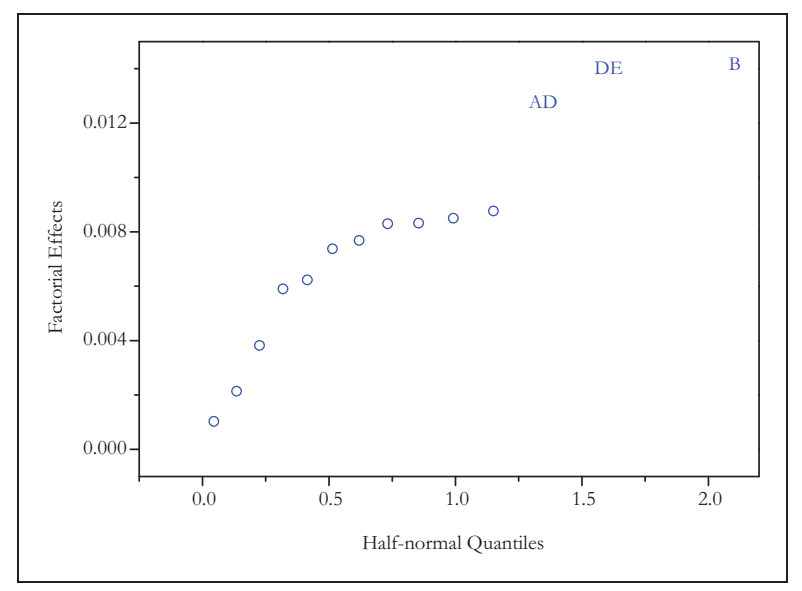

Figure 5. Half-normal plot (without A) for coefficient of friction (see Table 3 for factor labels). 


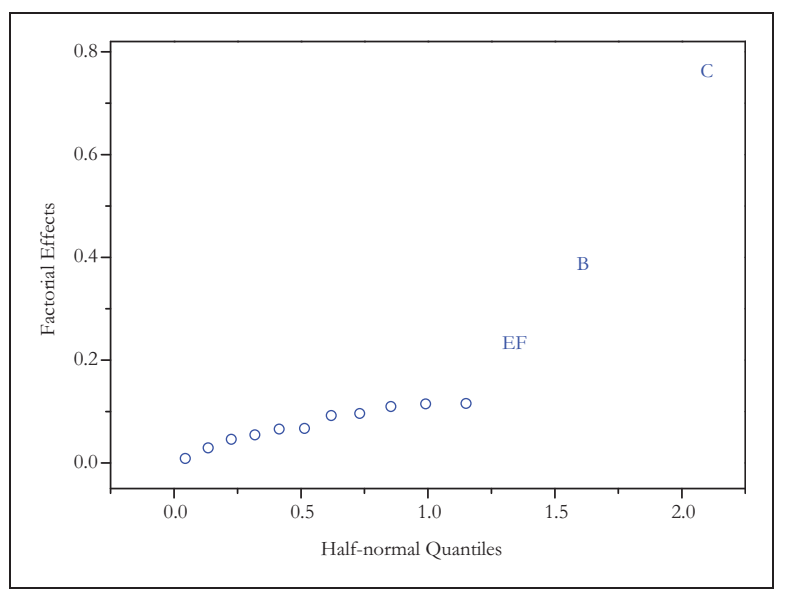

Figure 6. Half-normal plot (without A) for wear scar (see Table 3 for factor labels).

Wear scar. From the half-normal plot for wear scar diameter, shown in Figure 6, one aliased pair of interactions and two main effects are identified. The aliased pair of interactions is EF (sulphuric acid-moisture) with AC (disc material-soot). The main effects are of factor C (soot) and factor B (pin material).

For each response, if a main effect is identified of a factor that is involved in one or more identified interactions, then the main effect should not be interpreted, and these interaction(s) should be examined instead. This is because the main effect of a factor, formed from averaging effects over the levels of all the other factors, does not indicate how the effect of the factor depends on the level of another factor.

\section{Secondary experiment}

Six further runs were selected to gain further information, particularly about the aliased pairs of interactions which were identified in the first experiment. The six runs were chosen via a Bayesian optimal design methodology ${ }^{24}$ to maximise the information gain for the coefficient of friction and wear scar responses (see Table 6 for the test conditions), which were of most interest of tribological aspects in the first experiment. Results from the first experiment were used to inform this choice of design via construction of an informative prior distribution.

The results from the additional or secondary tests are shown in Table 7 . These were combined with the 16 runs (no midpoint levels were used as these were used for model checking) from the primary tests to produce a 22-run experiment. The data from these 22 runs were analysed and details of the outcome are shown below.

The analysis entailed the Bayesian fitting of linear statistical regression models that included both interactions from the aliased pairs identified as potentially important at the first stage (in addition to main effects). The statistical fitting was carried out using
Table 6. Test matrix for the six additional tests.

\begin{tabular}{lllrrll}
\hline & Parameter & & & & & \\
\cline { 2 - 6 } Run & A & B & C & D & E & F \\
\hline 21 & Silicon nitride & Silicon nitride & 0 & 0 & 2.5 & 0 \\
22 & Steel & Steel & 10 & 10 & 2.5 & 0 \\
23 & Steel & Silicon nitride & 10 & 0 & 0 & 2.5 \\
24 & Silicon nitride & Steel & 0 & 0 & 0 & 2.5 \\
25 & Silicon nitride & Steel & 10 & 10 & 2.5 & 0 \\
26 & Steel & Steel & 0 & 10 & 0 & 2.5 \\
\hline
\end{tabular}

Table 7. Results of the secondary series of test.

\begin{tabular}{|c|c|c|c|c|c|c|}
\hline \multirow[b]{2}{*}{ Run } & \multirow[b]{2}{*}{$\begin{array}{l}\text { Charge } \\
(\mathrm{pC})\end{array}$} & \multirow[b]{2}{*}{ COF } & \multicolumn{2}{|c|}{$\begin{array}{l}\text { Temperature } \\
\left({ }^{\circ} \mathrm{C}\right)\end{array}$} & \multirow[b]{2}{*}{$\begin{array}{l}\text { Wear scar } \\
\text { radius }(\mathrm{mm})\end{array}$} & \multirow{2}{*}{$\begin{array}{l}\text { Specific } \\
\text { wear rate } \\
\left(\mathrm{mm}^{3} / \mathrm{N} \mathrm{m}\right)\end{array}$} \\
\hline & & & $\begin{array}{l}\text { Steady } \\
\text { state }\end{array}$ & $\Delta \mathrm{T}$ & & \\
\hline 21 & 0.083 & 0.083 & 37.3 & 17.3 & 0.125 & $8.4 \mathrm{E}-\mathrm{II}$ \\
\hline 22 & 0.094 & 0.094 & 52.9 & 34.9 & 0.420 & I.IE-08 \\
\hline 23 & 0.100 & 0.100 & 55.2 & 37.2 & 0.215 & $7.4 \mathrm{E}-10$ \\
\hline 24 & 0.060 & 0.060 & 38.2 & 20.2 & 0.260 & 1.6E-09 \\
\hline 25 & 0.066 & 0.066 & 47.7 & 29.7 & 0.335 & 4.3E-09 \\
\hline 26 & 0.163 & 0.163 & 46.5 & 28.5 & 0.225 & $8.8 \mathrm{E}-10$ \\
\hline
\end{tabular}

COF: coefficient of friction.

bespoke computer code implemented in the R statistical programming language. ${ }^{25}$ The addition of six runs did not provide conclusive evidence of which interaction in an aliased pair is important but did allow tentative conclusions to be made.

All the effects plots below were generated by simulating responses from these fitted statistical models.

Charge. Factor A (disc material), which due to the limitation in the design cannot be formally assessed, has a very large factorial effect, as shown in Figure 7(a). Two other main effects were identified, but are not interpreted as these factors are involved in significant interactions. These are factors B (pin material) and D (oxidation)

Two interactions were identified BE (pin materialsulphuric acid), which is found to be statistically significant at the 5\% level and DE (oxidation-sulphuric acid), which is marginally significant (picked out by Chevron but not identified at the first stage) (see Figure 7(b)).

Coefficient of friction. Two main effects were identified, but are not interpreted as these factors are involved in significant interactions. These are factors A (disc material) and $\mathrm{B}$ (pin material), as shown in Figure 8(a). 
(a)
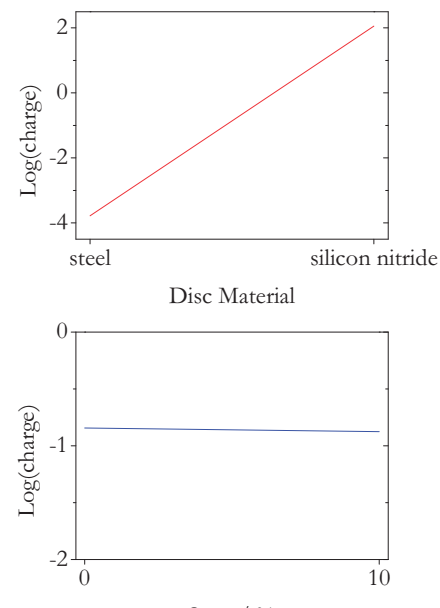

Soot $/ \%$

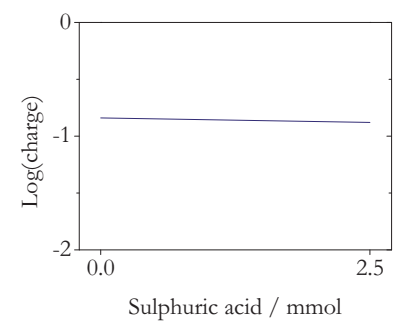

(b)
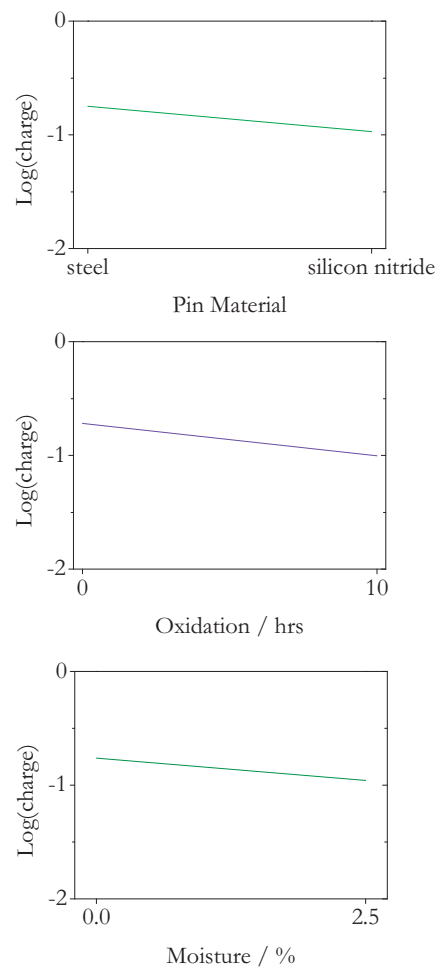

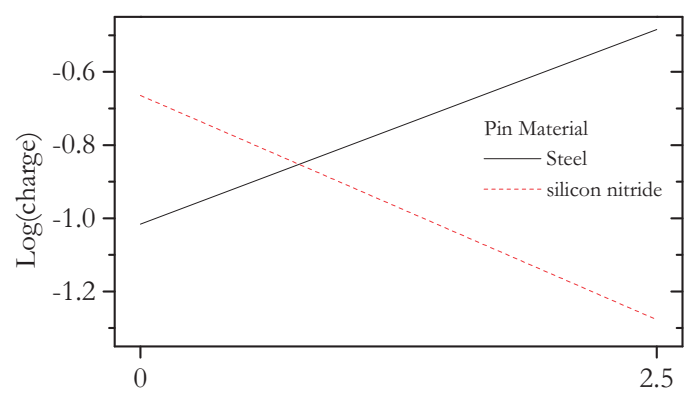

Sulphuric acid / mmol

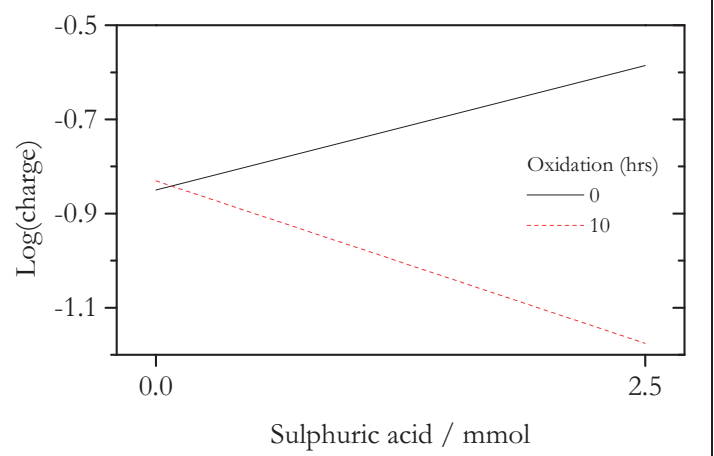

Figure 7. Factorial effects plots: (a) main factor effects and (b) interactions on measured charge levels (log scale).

(a)
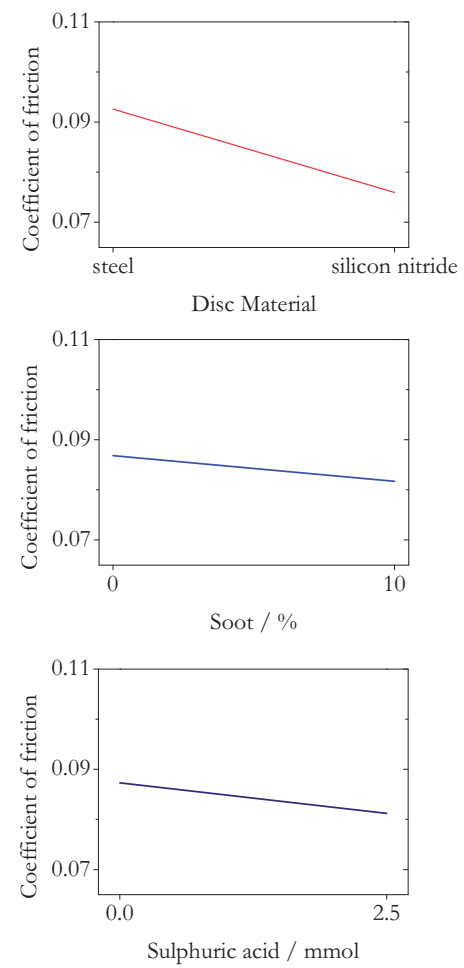

(b)
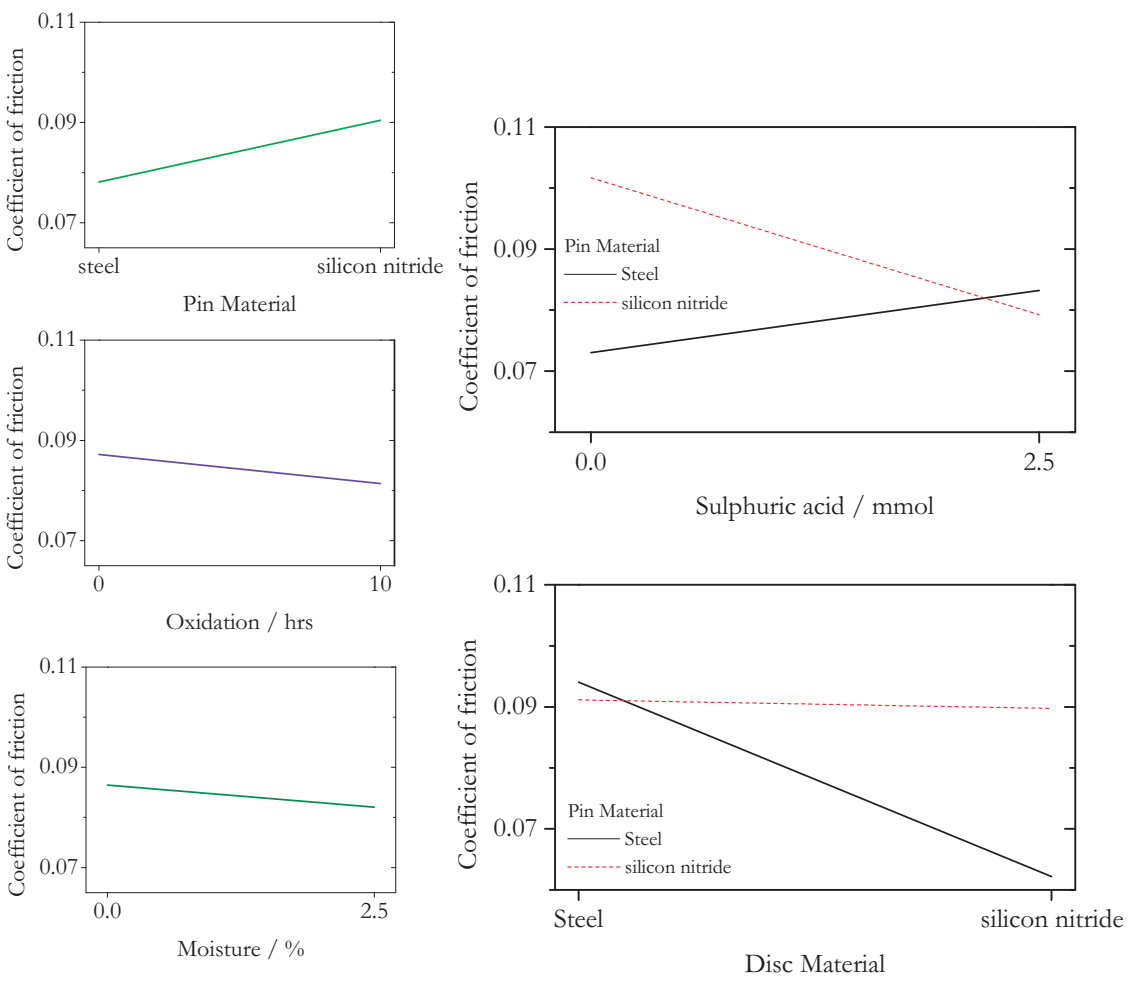

Figure 8. Main factor effects on coefficient of friction. 


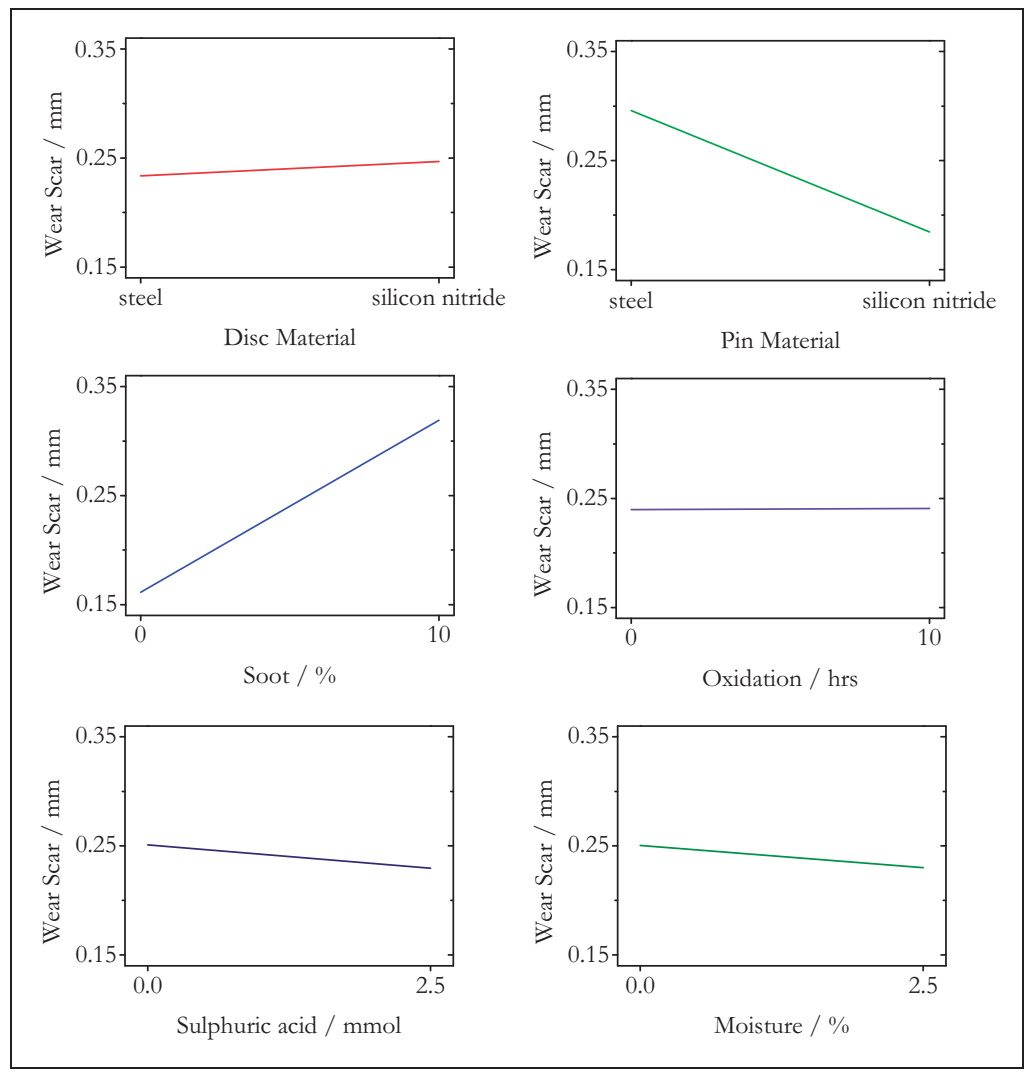

Figure 9. Main factor effects on measured wear scar diameter.

Two interactions were identified both of which were at statistically significant level: BE (pin material-sulphuric acid) and AB (disc material-pin material) (see Figure 8). A further interaction, $\mathrm{CE}$ (soot-sulphuric acid or soot-disc material), may be important but was not identified in the first stage, thus this full analysis (based on both stages of experiment) was not able to decouple them.

Wear scar. Two main effects were identified as statistically significant. These are factors B (pin material) and $\mathrm{C}$ (soot) as shown in Figure 9. No interactions were identified.

\section{Temperature}

Difference in temperature. The addition of the further six runs produced a much better fitting statistical model, with acceptable residual diagnostics. No interactions were identified and only one main effect, of soot contamination, was identified as significant in Figure 10. From the primary and full statistical analysis, the main effects and interaction of all factors are summarised in Table 8.

\section{Summary of findings from statistical analysis}

Post-test analysis. In post-test analysis, analysis of the pin wear scar was performed by identification of general descriptors and determination of commonality relating to these descriptors, without consideration of statistical analysis. Table 9 shows the commonalities found and Figure 11 shows typical examples of these features.

The same kind of analysis that was done in the optical analysis was applied to the SEM images as shown in Figure 12 and the commonalities are shown (see Table 10). The mostly found wear mechanisms are plastic deformation, abrasive, corrosive, pits and particulates on the pin wear samples. The plastic deformation predominantly with abrasive wear mechanism was observed on the steel pins with the presence of soot contaminant. The pro-abrasive and agglomeration behaviour of soot plastically damaged the pin surface as shown in Figure 12(a) for Run 3. The pro-abrasive nature of soot and tribochemical reaction of high level sulphuric acid attacked on the steel pins to have abrasive wear mechanism as shown in Figure 12(b). While the evidence of corrosion was observed only on the steel pins, which clearly indicates the role of sulphuric acid as shown in Figure 12(c). Interestingly, irrespective of the contaminants, smooth and particulates wear mechanism was observed on the silicon nitride pin and it is quite obvious that the silicon nitride pins are having higher hardness than the steel pin material. Whenever moisture contaminant is present in the contact surfaces, it causes pits like shown in Figure 12(e). 


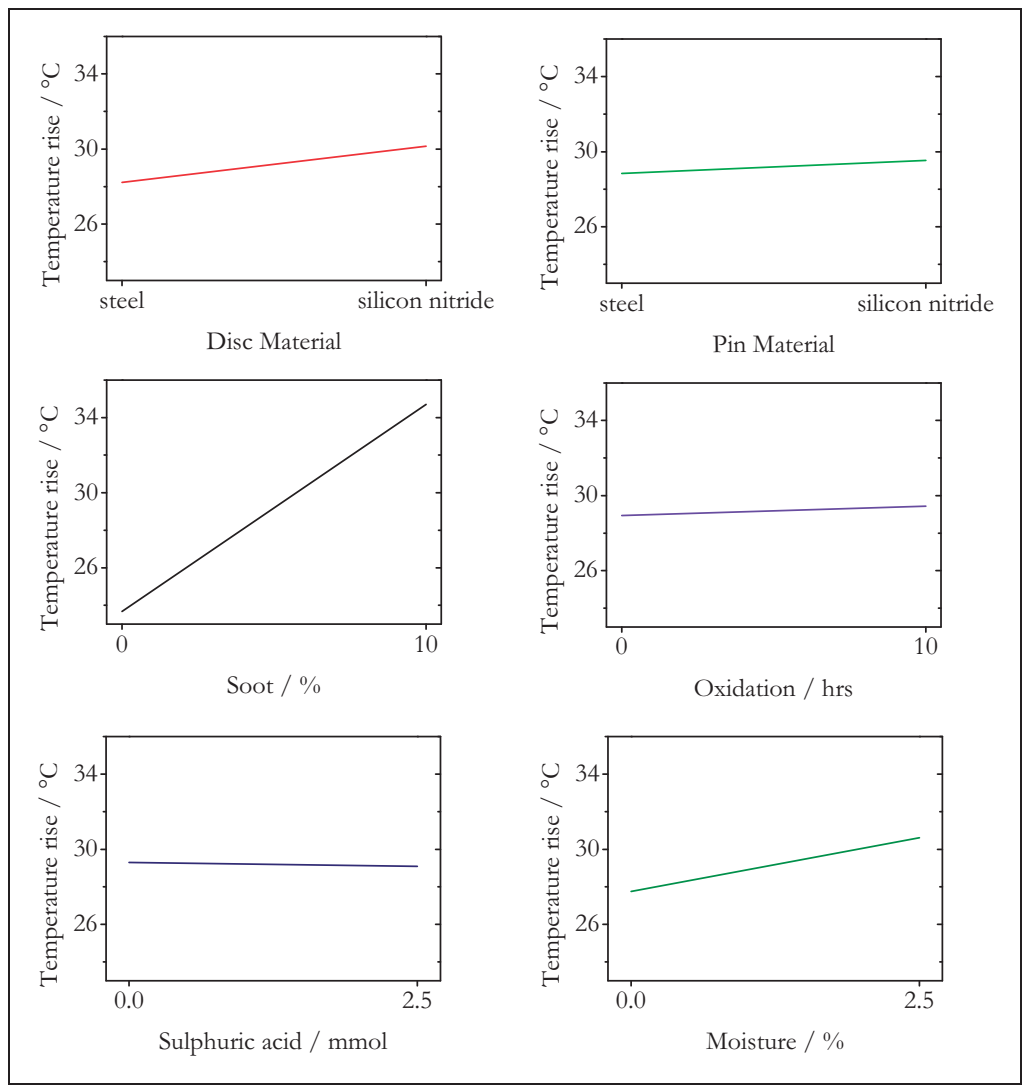

Figure 10. Factor main effects for disc surface temperature.

Table 8. Summary of online and wear rate data.

\begin{tabular}{|c|c|c|c|c|c|c|}
\hline & Parameter & Main effect & \multicolumn{2}{|c|}{ Interaction } & \multicolumn{2}{|c|}{ Aliased interaction } \\
\hline \multirow{5}{*}{$\begin{array}{l}\text { Primary } \\
\text { Statistical } \\
\text { analysis }\end{array}$} & Charge & Oxidation & \multicolumn{2}{|c|}{ Disc material-oxidation } & \multicolumn{2}{|c|}{ Pin material-sulphuric acid } \\
\hline & COF & Pin material & \multirow{2}{*}{\multicolumn{2}{|c|}{$\begin{array}{l}\text { Disc material-oxidation } \\
\text { Oxidation-sulphuric acid }\end{array}$}} & \multicolumn{2}{|c|}{ Pin material-sulphuric acid } \\
\hline & & & & & Dis & \\
\hline & Wear scar & Soot & \multicolumn{2}{|c|}{ Sulphuric acid-moisture } & \multicolumn{2}{|c|}{ Pin material-sulphuric acid } \\
\hline & Parameter & Main Effect & & Interaction & & \\
\hline \multirow{8}{*}{$\begin{array}{l}\text { Full statistical } \\
\text { analysis }\end{array}$} & \multirow[t]{3}{*}{ Charge } & Pin material & $\downarrow$ & Pin material-sulphuric acid ${ }^{a}$ & $\uparrow$ & $\downarrow$ \\
\hline & & Oxidation & $\downarrow$ & Oxidation-sulphuric acid ${ }^{\mathrm{b}}$ & $\downarrow$ & $\uparrow$ \\
\hline & & Disc material $^{c}$ & $\uparrow$ & & & \\
\hline & \multirow[t]{2}{*}{$\mathrm{COF}$} & Disc material & $\downarrow$ & Pin material-sulphuric acid ${ }^{\mathrm{a}}$ & $\uparrow$ & $\downarrow$ \\
\hline & & Pin material & $\uparrow$ & Disc material-pin material $^{\mathrm{a}}$ & $\downarrow$ & - \\
\hline & \multirow[t]{2}{*}{ Wear scar } & Pin material & $\downarrow$ & & & \\
\hline & & Soot & $\uparrow$ & & & \\
\hline & Temperature rise & Soot & $\uparrow$ & & & \\
\hline
\end{tabular}

COF: coefficient of friction.

The direction of the arrow indicates the direction of the main effect. For an interaction, the first arrow indicates the effect of increasing the value of the second factor when the first factor is set to its low level, and the second arrow indicates the effect of increasing the value of the second factor when the first factor is set to its high level.

${ }^{\text {a }}$ Statistically significant.

bMarginally significant.

Indicates that the factorial effect is large but cannot be formally assessed due to the limitations of the design. 
Table 9. General descriptors and their commonalities for optical images of pin wear scars.

\begin{tabular}{llll}
\hline General descriptor & Feature description & Pins & Commonalities \\
\hline $\begin{array}{l}\text { Rectangular scar } \\
\text { Polished scar }\end{array}$ & $\begin{array}{l}\text { Scars that are clearly not circular } \\
\text { Smooth scars }\end{array}$ & $\begin{array}{l}\text { I, 4, 6, 7 } \\
\text { II, I5, 16, 17, 18, 21 }\end{array}$ & $\begin{array}{c}\text { Steel disc, no soot } \\
\text { Silicon nitride pin on } \\
\text { silicon nitride disc }\end{array}$ \\
Entrainment feature & $\begin{array}{l}\text { Indentation damage at entraining } \\
\text { edge and sides of the pin }\end{array}$ & $3,5,9,13,14,19,20,22,24,25$ & Steel pin $^{\text {b }}$ \\
Horseshoe feature & $\begin{array}{l}\text { Development of deep grooves on } \\
\text { the shoulders of the scar }\end{array}$ & $2,4,6,7,8,23,26$ & Steel disc \\
\hline
\end{tabular}

${ }^{a}$ This is all of this material combination.

${ }^{\mathrm{b}}$ This is not all of the steel pins tested.
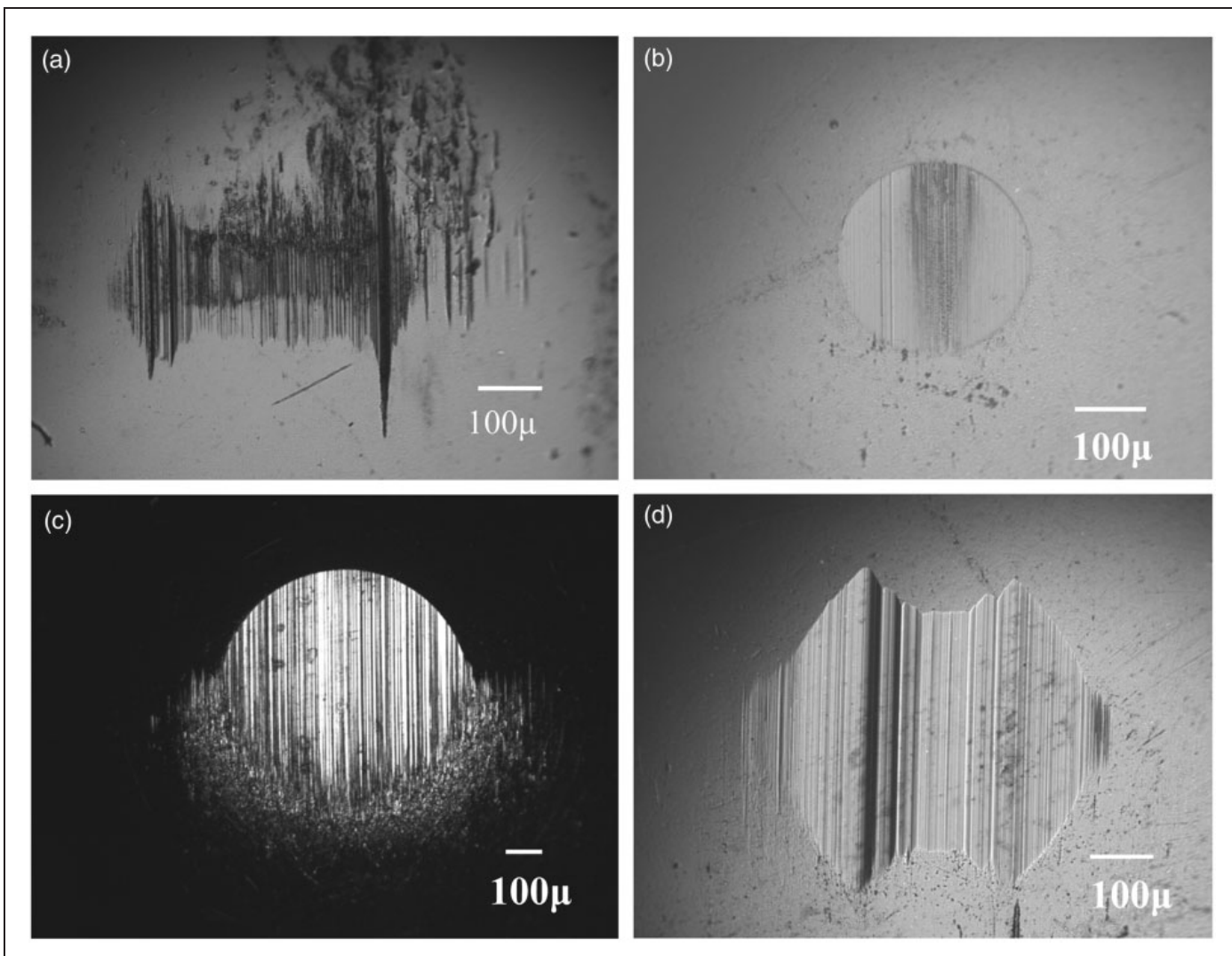

Figure II. Typical optical images of pin wear scars showing (a) rectangular scar (Run 4), (b) polished scar (Run I7), (c) entrainment feature (Run 19) and (d) horseshoe feature (Run 23).

The factorial study showed that charge was influenced by tribocouple material, the silicon nitride discs producing (much) higher charge than steel discs while the silicon nitride pins had a tendency to reduce charge when compared to steel pins. The high charge with a ceramic disc surface is to be expected as it is less conducting; it is sensitive to the silicon nitride pin but not so sensitive to the silicon nitride discs. Oxidation and moisture reduce charge as permittivity reduced and increased conductivity. The effect of oxidation alone investigated in the previous work indicates that charge is influenced only slightly by oxidation. This enhanced effect in the present study may be related to the interactions as discussed below. Acid and oxidation decrease charge unless steel wear occurs. In friction response, the silicon nitride disc gives lower friction, while the pins produce higher friction than their steel counterparts. This observation links to the lowest friction levels associated with steel pin on silicon nitride discs observed in the material combination analysis, although it is not known if the opposite relationship with charge is related.

The interactions for charge indicate that sulphuric acid will increase the charge for steel pins as the concentration increases, while for the silicon nitride pins the charge decreases. The post-test analysis indicates 


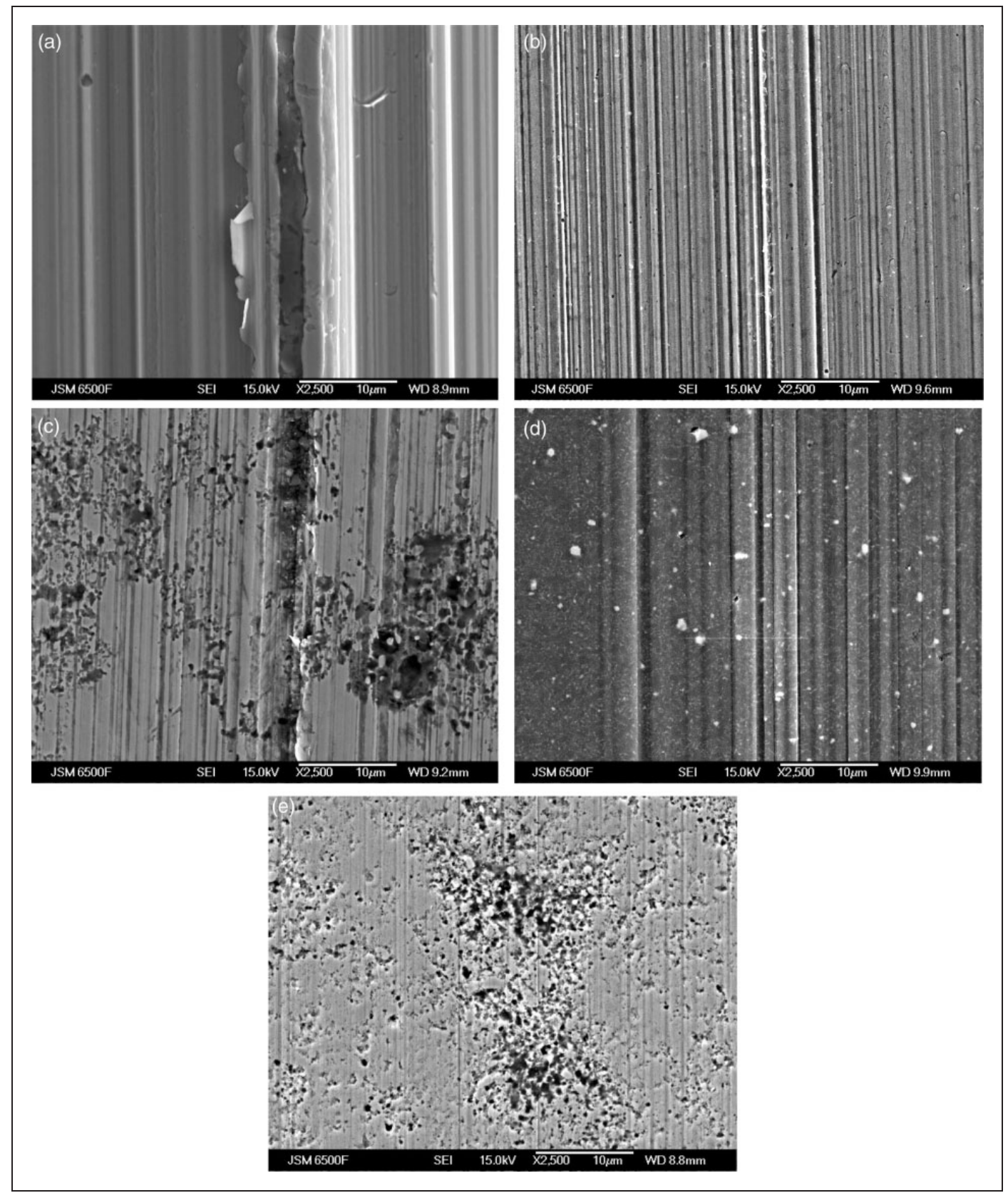

Figure 12. Typical SEM images of pin wear scars showing (a) plastic deformation (Run 3), (b) abrasive wear (Run I2), (c) corrosive wear (Run 19), (d) particulates (Run 8) and (e) pits (Run 14).

Table 10. General descriptors and their commonalities for SEM images of pin wear scars.

\begin{tabular}{|c|c|c|c|}
\hline General descriptor & Feature description & Pins & Commonalities \\
\hline Plastic deformation & $\begin{array}{l}\text { Evidence of plastic lipping and } \\
\text { extrusion }\end{array}$ & $3,5,9,19,22,25,26$ & Steel pin \\
\hline Abrasive & Evidence of abrasive grooving & $\begin{array}{l}2,3,4,6,7,8,10,12,13 \\
20,23,24,25\end{array}$ & $\begin{array}{l}\text { Generally steel pin, but mild version } \\
\text { observed for } \mathrm{Si}_{3} \mathrm{~N}_{4} \text { pins on steel discs. }\end{array}$ \\
\hline Corrosive wear & Evidence of corrosion & $4,5,6,12,13,17,26$ & Steel pin \\
\hline Pits & $\begin{array}{l}\text { Evidence of pitting, } \\
\text { chemical attack }\end{array}$ & $4,5,7,14,20$ & Moisture contamination \\
\hline Particulates & $\begin{array}{l}\text { Appearance of particles } \\
\text { on the surface }\end{array}$ & $\begin{array}{l}2,4,7,8,10,11,12,15 \\
\quad 16,17,18,21,23\end{array}$ & $\begin{array}{l}\text { Silicon nitride pin (except } 4,12- \\
\text { steel pin with sulphuric acid) }\end{array}$ \\
\hline
\end{tabular}


that the steel pins are susceptible to corrosive wear and pitting, both of which are tribochemical in nature, which conceivably would increase the charge observed, as tribochemical reactions involve ionic (charged) species. ${ }^{16}$

The other interaction involving charge also is affected by sulphuric acid and this time on oxidation. The low sulphuric acid gives a middle level of charge for both the oxidised $(10 \mathrm{~h})$ and non-oxidised states $(0 \mathrm{~h})$. Increasing the sulphuric acid level for the nonoxidised level produces an increase in charge, while the combination of oxidation and sulphuric acid reduces charge. This indicates that the acid is interacting or reacting chemically with the oxidised portions of the base oil or additive degradation products, which may be occurring in the bulk or on the surface.

For friction, one interaction is the same as one of the charge interactions: sulphuric acid will increase the friction (charge) for steel pins as the concentration increases, while for the silicon nitride pins the friction (charge) decreases. This indicates that the process(es) involved are clearly linked and surface oriented.

The other friction interaction of disc and pin material has been explored and correlated with both the main effects, material combination analysis and post-test analysis. This clearly shows that the materials used and particularly the combination of materials is important.

At this stage, use of a fractional factorial made the multifactor study practicable within time and resource constraints. The application of a sophisticated followup design enabled the decoupling of pairs of aliased interactions which had been identified as potentially important. Use of a larger experiment, for example using the full factorial design, would have allowed for higher order interactions to have also been investigated but at much greater experimental cost.

\section{Conclusions}

The main contributions from this factorial study of diesel engine contamination effects are summarised as follows:

- Among all contaminants and materials, soot and pin material are major reason for wear in tribological contacts.

- The interactions between pin-disc materials and pin material-sulphuric acid influence friction response in tribological contacts.

- From post-test analysis, steel pins are more prone to abrasive and corrosion wear than silicon nitride pins.

\section{Acknowledgements}

The authors wish to thank Chevron Oronite Company for supplying the test oils, oxidation oils and soot to carry out this research work. We would like to thank Mr Kenneth D
Nelson for his valuable inputs and suggestions during the results and discussion.

\section{Declaration of Conflicting Interests}

The author(s) declared no potential conflicts of interest with respect to the research, authorship, and/or publication of this article.

\section{Funding}

The author(s) received no financial support for the research, authorship, and/or publication of this article.

\section{ORCID iD}

P Ramkumar (D) http://orcid.org/0000-0002-2816-9145

\section{References}

1. Snelling DR, Smallwood GJ, Sawchuk RA, et al. Particulate matter measurements in a diesel engine exhaust by laser-induced incandescence and the standard gravimetric procedure. SAE Technical paper 199901-3653, 1999.

2. Truhan JJ, Qu J and Blau PJ. The effect of lubricating oil condition on the friction and wear of piston ring and cylinder liner materials in a reciprocating bench test. Wear 2005; 259: 1048-1055.

3. Smiechowski MF and Lvovich VF. Electrochemical monitoring of water-surfactant interactions in industrial lubricants. $J$ Electroanal Chem 2002; 534: 171-180.

4. Murakami Y. Analysis of corrosive wear of diesel engines: relationship to sulfate ion concentrations in blowby and crankcase oil. JSAE Rev 1995; 16: 43-48.

5. Needleman WM and Madhavan PV. Review of lubricant contamination and diesel engine wear. SAE paper 881827, 1988.

6. Singh SK, Agarwal AK, Srivastava DK, et al. Experimental investigation of the effect of exhaust gas recirculation on lubricating oil degradation and wear of a compression ignition engine. ASME $J$ Eng Gas Turbines Power 2006; 128: 921-927.

7. Akiyama K, Manunaga K, Kado K, et al. Cylinder wear mechanism in an EGR-equipped diesel engine and wear protection by engine oil. SAE paper 872158 , 1987.

8. Bowman WF and Stachowiak GW. Determining the oxidation stability of lubricating oils using sealed capsule differential scanning calorimetry (SCDSC). Tribol Int 1996; 29: 27-34.

9. Yamaguchi ES, et al. The Relative Oxidation Inhibition Performance of Some Neutral and Basic Zinc Dithiophosphate Salts. Tribol Trans 1999; 42: 895-901.

10. Box GEP, Hunter JS and Hunter WG. Statistics for experimenters: design, innovation and discovery. Chapter 5. Hoboken, NJ: Wiley, 2005.

11. Harvey TJ, Wood RJK, Denuault G, et al. Investigation of electrostatic charging mechanisms in oil lubricated tribo-contacts. Tribol Int 2002; 35: 605-614.

12. Harvey TJ, Morris S, Wood RJK, et al. Real-time monitoring of wear debris using electrostatic sensing techniques. Proc IMechE, Part $J: \quad J$ Engineering Tribology 2007; 221: 27-40. 
13. Wang L, Wood RJK, Harvey TJ, et al. Wear performance of oil lubricated silicon nitride sliding against various bearing steels. Wear 2003; 255: 657-668.

14. Morris S, Wood RJK, Harvey TJ, et al. Electrostatic charge monitoring of unlubricated sliding wear of a bearing steel. Wear 2003; 255: 430-443.

15. Wood RJK, Ramkumar P, Wang L, et al. Electrostatic monitoring of the effects of carbon black on lubricated steel/steel sliding contacts. Tribol Interface Eng Ser 2005; 48: 109-121.

16. Penchaliah R, Harvey TJ, Wood RJK, et al. The effects of diesel contaminants on tribological performance on sliding steel on steel contacts. Proc IMechE, Part J: J Engineering Tribology 2011; 225: 779-797.

17. Pérez AT and Hadfield M. Low-cost oil quality sensor based on changes in complex permittivity. Sensors 2011; 11: $10675-10690$.

18. Hearn GL. Electrostatic ignition hazards arising from fuel flow in plastic pipes. J Loss Prev Proc Ind 2002; 15: 105-109.

19. McGeehan JA and Ryason PR. Preventing catastrophic camshaft lobe failures in low emission diesel engines. SAE paper 2000-01-2949, 2000.
20. Mufti RA and Priest M. Experimental and theoretical study of instantaneous engine valve train friction. J Tribol 2003; 125: 628-637.

21. Bell JC. Gasoline engine valve train design evolution and the anti-wear requirements of motor oils. Proc IMechE, Part J: J Engineering Tribology 1998; 212: 243-257.

22. Goos P and Jones B. Optimal design of experiments: a case study approach. Chapter 10. Hoboken, NJ: Wiley, 2011.

23. Wu CFJ and Hamada MS. Experiments: planning, analysis and optimization. New York: Wiley, 2009, p.177.

24. Rose AD. Bayesian experimental design for model discrimination. PhD Thesis, University of Southampton, UK, 2008.

25. R Core Team. R: a language and environment for statistical computing. Vienna: R Foundation for Statistical Computing, https://www.R-project.org/ (2018, accessed 23 October 2017). 